\title{
THE EFFECT OF BLEACHING AND BACKGROUNDS ON PUPIL SIZE
}

\author{
M. Alpern and N. OhiBA ${ }^{1}$ \\ Vision Research Laboratory, Departments of Ophthalmology and Physiology, \\ University of Michigan Ann Arbor, Michigan 48104
}

(Received 9 October 1971)

\section{INTRODUCTION}

THE SURPRISING possibility that the widening of the human pupil in the dark accurately reflects regeneration of rhodopsin in the retinal rods was first suggested by the experiments of ALPERN and CAMPBell (1962a). They found that recovery of the pupil size in the dark after a full rhodopsin bleach was very slow. After an initial transient widening and narrowing in the first minute, the pupil returned to the fully dark-adapted size "along a curve very similar to that of rod dark adaptation". The action spectrum of this effect showed it to be dominated by rods. Transient pressure blindness of the bleached (but never the unbleached) eye transiently widened the pupil to its fully dark value.

The time course of the recovery of pupil size in the dark after a full bleach was accurately described by an exponential curve with a time constant of about $6 \mathrm{~min}$. The inference that signals generated by the amount of unregenerated rhodopsin sets the size of the pupil in the dark, rested on the observation (RUSHTON, 1961) that rhodopsin regeneration after a full bleach follows this same sort of recovery time course in the dark. If the agreement were exact, then pupil size could be used effectively as a retinal densitometer and it would follow that

$$
\Delta D=\Delta D_{o}(1-p) .
$$

$\Delta D$ is the differences between the pupil diameter after full dark adaptation and the dia. at any other moment $(t)$ in the dark after a full bleach; $\Delta D_{o}$ is the maximum difference in dia. found by extrapolation to the diameter at the moment the light was extinguished (ignoring the initial transient widening and constriction), and $p$ is the fraction of rhodopsin regenerated at $t$.

Equation (1) is of some theoretical-as well as practical-interest, but the evidence in support of its validity is not compelling. In the first place, Alpern and Campbell's comparison was only approximate and the rhodopsin regeneration was measured under different circumstances and on quite different subjects than the pupil size recovery. In the second place, BorgmanN (1967) and Newsome (1971) have since found slightly faster pupil recoveries, though Borgmann's bleaches were too weak and Newsome's field was considerably smaller than that used by Alpern and Campbell.

In the first part of this paper we established the validity of equation (1) directly by producing full rhodopsin bleaching in a ganzfeld and following the subsequent recovery of

${ }^{1}$ On leave from the Department of Ophthalmology, University of Tokyo, Tokyo, Japan. 
pupil size in the dark with a pupillometer and the regeneration of rhodopsin with the retinal densitometer in the same subjects. In the second part we use equation (1) as a transform together with current ideas of visual adaptation (RUSHTON, 1965) to predict the pupil size in the steady state with uniform illumination of the entire visual field (independent of any eye movements).

\section{METHOD}

The rhodopsin measurements with the Florida model of the retinal densitometer (HoOD and RusHTON, 1971) were a direct extension of experiments described elsewhere (ALPERN, 1971).

The diameter of the pupil was measured by the infrared television pupillometer of GreEN and MAASEIDVAAG (1967). This provides estimates of pupil size in total darkness 30 times per sec with a precision of $0.01 \mathrm{~mm}$.

The size of the pupil of the left eye was determined at various moments in the dark after a full bleach of the retina of the right eye until the fully wide pupil of the dark adapted eye was achieved. These experiments were essentially a repeat of those of AlPERN and CAMPBell (1962a). Here, however, the entire retina was bleached by exposing the right eye to $6.7 \log$ scotopic td for $3 \mathrm{~min}$. This was seen on a white diffusing ganzfeld (in the form of a half ping-pong ball) completely filling the visual field. The pupil of the right eye was fully dilated with $1 \%$ tropicamide. The subject placed himself so that the ping-pong ball immediately in front of the eye was about $1.5 \mathrm{in}$. from the projection lens of an ordinary $35 \mathrm{~mm}$ lantern slide projector with its $300 \mathrm{~W}$ tungsten filament lamp energized. It generally took several seconds before he was able to keep his eyelid fully open and he was allowed to take as much time as he needed to do this. The clock was started when he signalled that he was ready. At the end of a 3-min exposure, the subject placed himself in the pupillometer while the projector was turned off. Measurements in the dark followed for the subsequent $30-40 \mathrm{~min}$.

In the second part, the pupil dia. of the left eye was measured under equilibrium conditions at a variety of different luminance levels. Starting with full dark adaptation, the ping-pong ball over the right eye was illuminated by the dimmest intensity of light from an automobile head lamp attenuated by Wratten No. 96 neutral filters $(4 \times 4 \mathrm{in}$.). The subject adapted for several minutes to this level of illuminance before records of pupil diameter were made. In order to shorten the time required to reach the steady state at levels of illuminance which bleach measurable rhodopsin, it is possible to precede the equilibrium exposure by a 10 -sec light which is $1.0-1.5 \log _{10}$ units brighter. When this method was used, 1 min exposure to the weaker (equilibrium) intensity preceded the beginning of pupil size measurements. Although subjects made a special effort to avoid blinking, several blinks usually occurred in each recording interval. No recordings were analyzed within the neighborhood of the blinks. Upon illumination, the pupil constricted and, once equilibrium was reached, oscillated around the equilibrium level with a small amount of "hippus" which varied with the subject and state of fatigue as well as, to some extent with illumination. After a blink the equilibrium level was achieved once more well within a 10-sec interval during which the record was not analyzed. This same procedure was followed for each of a variety of illuminance levels, the experiment always proceeding progressively from the dimmest to the brightest level. About 50 representative measurements were obtained from the recordings at each level, in each experimental session. Such data represent the size of the pupil of the eye viewing a uniform ganzfeld under equilibrium illuminance with a stablized retinal image. Since the semi ping-pong ball is not a perfect diffuser, there are some constraints upon this interpretation of our results. However, this difficulty was largely obviated by requiring the subject to hold his eye relatively fixed during the recording.

\section{RESULTS}

\section{Part 1. Dilation in the dark}

AlPERn and CAMPBell (1962a) found, and we confirm, that during the first minutes in the dark the pupil widens and then narrows before it starts the slow dilation process. The first two phases have been studied to some extent by Newsome (1971). Only the last phase is of concern in this paper.

The dots in Fig. I show the recovery of pupil size in the dark during single experimental runs for each of three observers. In this figure, the ordinates (scale to the left) give the amount of pupil constriction $(\Delta D)$, over the full dark value, while the abscissae show the time in the dark after a full rhodopsin bleach. This recovery curve is in good agreement with 
AlPERN and CAMPBelL's (1962a) result. They inferred that it was generated by signals (B) of the amount of unregenerated rhodopsin in bleached rods. This interpretation is confirmed by the open circles in Fig. 1 which show for the same three subjects the regeneration of rhodopsin (ordinate scale to the right) in their retinas after long full bleaches. A single smooth curve described the results of both experiments equally well. It is an exponential with a time constant of about $400 \mathrm{sec}$. Hence, there is a linear relation between the fraction of unregenerated rhodopsin, $(1-p)$, and the change in the diameter of the pupil in the dark after a full bleach, [equation (1)].

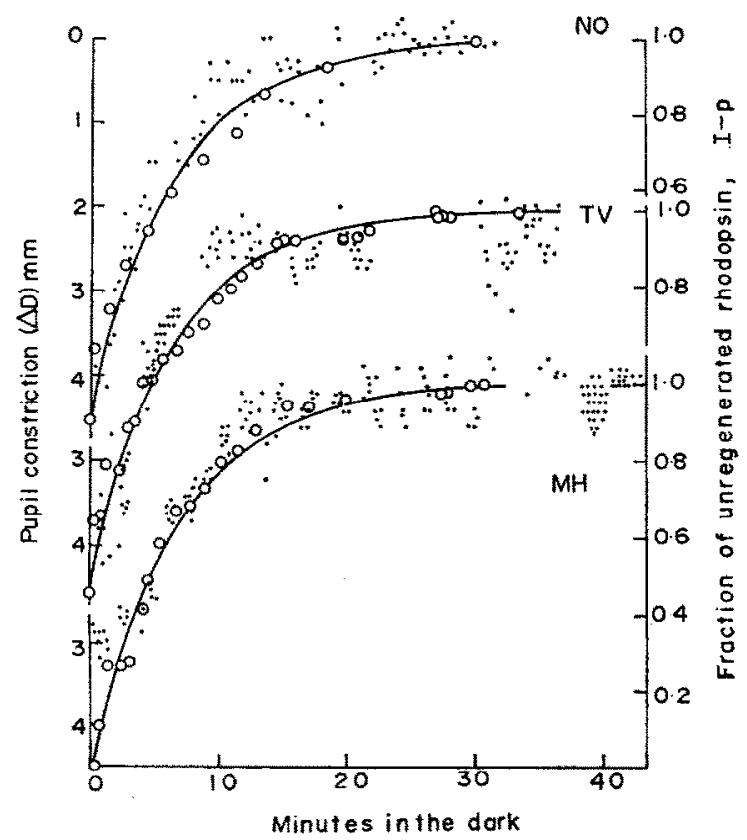

Frg. 1. Recovery of pupil size after full ganzfeld bleaching as a function of time in the dark. The dots represent the change in pupil dia. (ordinate scale to the left) with the dia. in full dark adaptation set equal to zero. Circles represent regeneration of rhodopsin after a full bleach, for the same three subjects-N.O. (top), T.V. (middle), and M.H. (below), respectively. Ordinate scale to the left. The smooth curve is an exponential with a time constant of $400 \mathrm{sec}$. The results are from single experimental runs (though densitometry and pupillography were done in separate sessions).

These results show that, under such conditions, the pupil diameter changes linearly with rhodopsin concentration; and may, in effect, be used as a rhodopsin densitometer. This is not the case, however, when the eye is exposed to real backgrounds, even under the least complex of circumstance, as the following experiments emphasize.

Part 2. The pupil size in the steady state

In the first part of this paper, the relation between pupil size in the dark after a full bleach and the amount of rhodopsin in the retina [equation (1)] was determined empirically. In this part it is used to predict the pupil size $(D)$ in equilibrium at a variety of illuminance levels, covering a range between those which are barely perceptible and those which bleach more than 80 per cent of the exposed rhodopsin. 


\section{Theory}

RushroN's (1965) model of adaptation is used (Fig. 2). In this model, retinal sensitivity is regulated by an automatic gain control device (similar to that proposed by FuorTes and HoDGKIN (1964) to explain the generator potential of the Limulus lateral eye). The input to the device is proportional to the steady background light of intensity $I$ while the output, $V$, is approximately proportional to $\log I$. The output is sent to the brain (and to the iris muscles of the two eyes); but, it is also fed back to the automatic gain control to regulate sensitivity. Signals, $B$, to the brain (and to the iris muscles of the two eyes) from bleaching proportional to the amount of unregenerated rhodopsin $(1-p)$ do not go through the

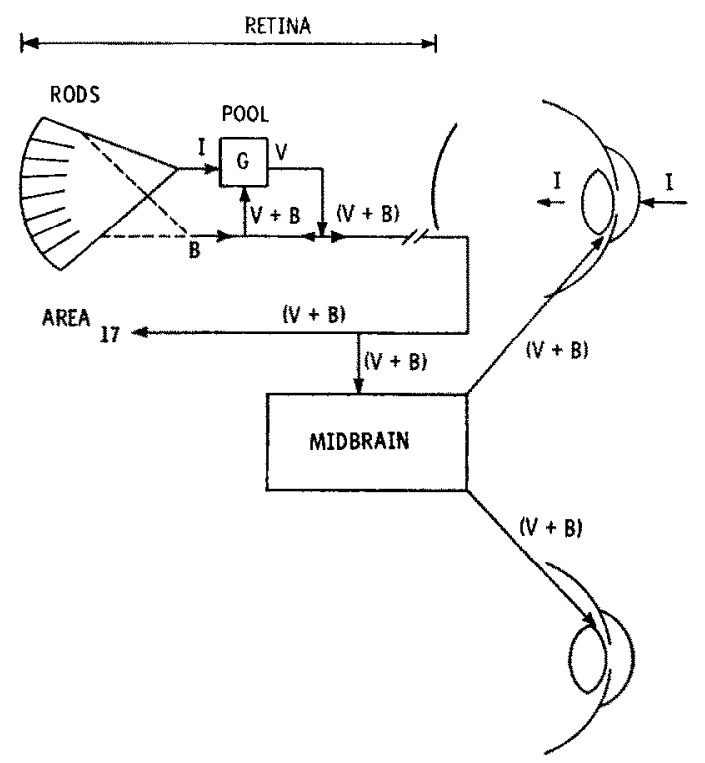

FIG. 2. Schematic drawing of the model used to explain the effects of bleaching and backgrounds on pupil size. Rods feed signals to the pool proportional to the background intensity $I$. The output $V$ (proportional approximately to the $\log I$ ) passes to the optic nerve and is fed back to regulate sensitivity. Bleaching signals $(B)$ proportional to the unbleached rhodopsin enter the gain control from the feedback, but also pass to the brain via the optic nerve. The change in pupil diameter is proportional to the sum $(V+B)$.

automatic gain control device, though they go into it through the feedback, in order to regulate the sensitivity of the retina in the dark after strong bleaches. This provides an explanation for the equivalance of background and bleaching in elevating threshold, demonstrated by Strles and CRAWFORD, (1932) and by CRAWrord, (1947). Pupil size changes are here assumed to be the sum of the changes produced by $V$ and those produced by $B$. (See derivation in the appendix). This leads directly to:

$$
D=D^{\prime}-\Delta D_{0}\left[\frac{I}{I+I_{0}}+\frac{1}{\alpha} \log \left(I+I_{D}\right)+k\right] .
$$

$D^{\prime}$ is the pupil dia. in full dark adaptation and $I$ is the equilibrium intensity of the uniformly illuminated ganzfeld (in scotopic td). $\mathrm{I}_{o}, \alpha, \mathrm{I}_{D}$ and $k$ are constants all of which 
in principle can be obtained by independent experiments, though technical difficulties make it practical in the present case to determine only the first two in this way.

\section{RES ULTS}

The size of the pupil in the steady state is plotted as a function of the logarithm of the retinal illuminance in Fig. 3. These results are for the same three subjects whose recoveries in the dark were studied in Fig. 1. The smooth curve through these data is described by equation (2) and no adjustment of the constants to accommodate individual differences has been made. The agreement is reasonable enough to suggest that the theory may be along the right lines.

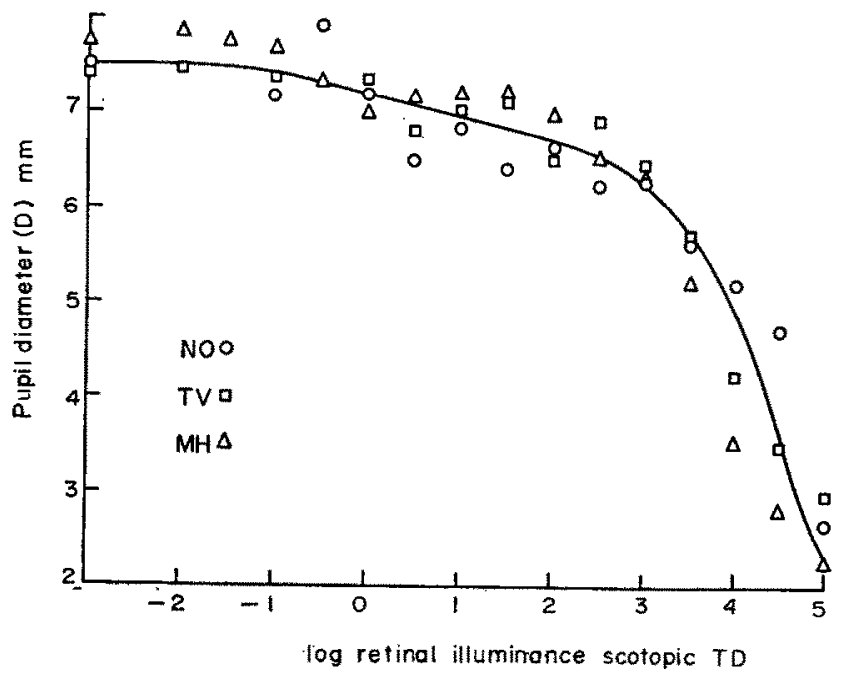

FIG. 3. The pupil diameter at equilibrium illumination in a ganzfeld for the three subjects studied in Fig. 1. The results for T.V. (square) are the means of two experimental repetitions, those for N.O. (circles) are the means of three while those for M.H. (triangle) are from a single experiment. The smooth curve is described by equation (2) with the constants assigned in the way described in the appendix. No arbitrary shifting of the data, or adjustment of constants, has been made in order to adjust for intra individual differences.

\section{DISCUSSION}

Figure 1 contains the major finding of this paper, namely that in the dark after a full bleach of the entire retina, there is a linear relation between the size of the pupil and the fraction of rhodopsin unregenerated. It is important to emphasize that this empirical relation is valid only for the limited experimental conditions used here. Reducing either the amount of rhodopsin bleached or the size of the bleaching area may cause a failure of equation (1).

Quantitative analysis of the limiting conditions of equation (1) are still to be worked out, but from the evidence already available, it seems clear that the limitation imposed by bleaching is the more important. Even as large a bleach as 50 per cent suffices to show a clear breakdown in equation (1) (OHBA, 1971). On the other hand, the ALPERN and CAMPBELL (1962a) result makes it apparent that equation (1) will hold equally for a ganzfeld and a $40^{\circ}$ centrally fixed field, and Newsome's (1971) recovery curve, after a full bleach of a 
central retinal region $17 \times 20^{\circ}$, is only slightly fast-reaching the full dark pupil size in 15-18-instead of $30 \mathrm{~min}$.

The agreement shown in Fig. 3 between the results and the theoretical curve is good enough to regard equation (2) and the theory from which it was derived as an approximate description of the relation between pupil size and intensity in equilibrium uniform ganzfeld illumination. But, in at least three ways, the theory is almost certainly an over-simplification. It neglects: (i) cone contribution to equilibrium pupil size in full ganzfeld illumination; (ii) rod saturation produced by the equilibrium background; and (iii) saturation of the photopupil response imposed by the limitations of the iris muscles.

The last is only a difficulty at the very highest levels, where the theory breaks down in any event, because of the transient pupil widening and narrowing in the first minute in the dark during which time about 15 per cent of the rhodopsin regenerates after a full bleach. At equilibrium, a background of about $5 \cdot 2 \mathrm{log}$ scotopic td bleaches 85 per cent of the rhodop$\sin$ and there is no justification for applying the present explanation at backgrounds at, or above, these levels.

Rod saturation (AGUILAR and STILES, 1954) can readily be incorporated in the theory, but the quantitative changes in the fit by doing so (though they are improvements) are relatively trivial and it seems unimportant to include them in a theory which attempts only a first approximation.

There can be no doubt that cones contribute to steady state pupil size if the test field is small (TEN Doesschate and AlPERn, 1965). AlPERn and CAMPBell (1962b) found the pupil action spectrum for an $8^{\circ}$ field centrally fixed to be the geometric mean of the rod and cone sensitivities. For even smaller fields ( $1^{\circ}$ ), ALPERN and BENSON (1953) found that the directional sensitivity of the pupillomotor photoreceptors in steady sate foveal viewing was the same as that of the foveal cones measured psychophysically. For larger fields, this cone contribution becomes swamped by the rods, so that for a $53^{\circ}$ centrally fixed field, the photopupil response shows little or no sensitivity to the angle of incidence of the light on the retina (SPRING and STILES, 1948); and with a full hemisphere illumination, the action spectrum of the steady state pupillomotor response is that of rods alone (BoumA, 1963). Thus, in the present case with full ganzfeld illumination, it seems unlikely that we are led very far astray by a theory which neglects the cone contribution to the steady state pupil size.

Even with these limitations, the agreement between theory and experiment shown in Fig. 3 suggests that the adaptation processes for vision and photopupillary motion must be very similar. This is an important inference if true, but a more exact comparison requires the analysis of pupil responses to flashes of light. This is the subject of the following paper (OHBA and ALPERN, 1972). There it is shown that the equivalence of bleaching and backgrounds established psychophysically at threshold for vision is equally valid for the pupil even several log units above threshold.

\section{REFERENCES}

Agullar, M. and Stiles, W. S. (1954). Saturation of the rod mechanism of the retina at high levels of stimulation. Optica Acta 1, 59-65.

AlPERn, M. (1971). Rhodopsin kinetics in the human eye. J. Physiol., Lond. 217, 447-471.

AlPERN, M. and BENson, D. J. (1953). Directional sensitivity of the pupillomotor photoreceptors. Am. J. Optom. 30, 569-580.

AlPERN, M. and CAMPBelt, R. W. (1962a). The behaviour of the pupil during dark-adaptation. J. Physiol., Lond. $165,5-7 \mathrm{p}$.

ALPERN, M. and CAMPBELL, F. W. (1962b). The spectral sensitivity of the consensual light reflex. J. Physiol., Lond. 164, 478-507. 
AlPeRn, M., Rushton, W. A. H. and TORI, S. (1970). The attenuation of rod signals by bleaching. $J$. Physiol., Lond. 207, 449-461.

BARLow, H. B. (1957). Increment thresholds at low intensities considered as signal/noise discriminations. J. Physiol., Lond. 136, $469-488$.

Borgmann, H. (1967). Das Verhalten des Pupillendurchmessers in Dunkelheit nach verschieden langer Vorbelichtung. Albrecht v. Graefes Arch. Ophthal. 172, 220-228.

Bouma, H. (1964). Rcceptive systems mediating certain light reactions of the pupil of the human eye. Thesis, Eindhoven, Holland.

Crawrord, B. H. (1947). Visual adaptation in relation to brief conditioning stimuli. Proc. R. Soc. B. 134, 283-302.

Fuortes, M. G. F. and Hodgkins, A. L. (1964). Changes in time scale and sensitivity in the ommatidia of Limulus. J. Physiol., Lond. 172, 239-263.

Green, D. G. and MaAseidvaAg, F. (1967). Closed-circuit television pupillometer. J. opt. Soc. Am. 57, 830-833.

Hood, C. and Rushron, W. A. H. (1971). The Florida retinal densitimeter. J. Physiol., Lond. 217, 213-229.

Newsome, D. A. (1971). Afterimage and pupillary activity following strong light exposure. Vision Res. 11, 275-288.

OHBA, N. (1971). Effect of the intensity of light adaptation on the rate of recovery of maximum pupil size in the dark. Acta Soc. ophthal. jap. 75 Suppl. 689-692.

OHBA, N. and AlPERN, M. (1972). Adaptation of the pupil light reflex. Vision Res. 12, 953-967.

Rushron, W. A. H. (1961). Rhodopsin measurement and dark-adaptation in a subject deficient in cone vision. J. Physiol., Lond. 156, 193-205.

Rushron, W. A. H. (1965). Visual adaptation: The Ferrier Lecture. Proc. R. Soc. B. 162, 20-46.

SPRING, K. H. and STILES, W. S. (1948). Variation of pupil size with change in the angle at which the light stimulus strikes the retina. Br.J. Ophthal. 32, 340-346.

StILES, W. S. and Crawford, B. H. (1932). Equivalent adaptation levels in localized retinal areas. Rep. Discuss. Vision phys. Soc. (Lond), 194-211.

TEN DOesschate, J. and ALPERN, M. (1965). Response of the pupil to steady-state retinal illumination: contribution of cones. Science, N.Y. 149, 989-991.

\section{APPENDIX}

To predict $D$ the size of the pupil of an eye viewing a full uniform ganzfeld in the steady state, assume that the constriction due to the bleaching signal $\Delta D_{b}$ and the constriction due to the output of the automatic gain control $\Delta D_{v}$ add linearly. Hence,

$$
D=D^{\prime}-\left(\Delta D_{v}+\Delta D_{b}\right)
$$

To compute $\Delta D_{v}$ we rely on the fact discovered by RusHron (1961) on the rod monochromat and confirmed on the rod monochromat by ALPERN (1971) and on the normal by ALPERN, RusHTon and TORRI (1970) that in the dark after a full bleach, the log threshold is proportional to the fraction of unbleached rhodopsin.

$$
\log \Delta I / \Delta I_{0}=a(1-p),
$$

in which $\Delta I$ is the threshold at any moment in the dark after a full bleach and $\Delta I_{o}$, the threshold after full dark adaptation. In the presence of steady backgrounds, the threshold follows Weber's Law

$$
\Delta I=F\left(I+I_{D}\right),
$$

where $F$ is the Weber-Fechner fraction (in seconds); $I$, the equilibrium background intensity, and $I_{D}$, the dark light of the retina (BARLOW, 1957). The concept of the equivalence of bleaching and real backgrounds (Stiles and Crawford, 1932; CraWford, 1947; Rushton, 1965) allow us to equate $\Delta I$ in equations (ii) and (iii). This gives

$$
(1-p)=\frac{1}{a}\left[\log \frac{F}{\Delta I_{o}}+\log \left(I+I_{D}\right)\right]
$$

which can be substituted in equation (1) to give

$$
\Delta D_{v}=\frac{\Delta D_{o}}{a}\left\{\log \frac{F}{\Delta I_{o}}+\log \left(I+I_{D}\right)\right\}
$$

since $\Delta D=\Delta D_{v}$.

Finally, we compute the constriction due to the bleaching signal produced by real backgrounds. This is derived directly from the densitometer measurements of the amount of pigment bleached at equilibrium 
by a steady light of intensity 1 . ALPERN (1971) showed that the results of such experiments are well described by the equation

$$
1-p=\frac{I}{I+I_{0}}
$$

$I_{o}$ is the background intensity which bleaches 50 per cent of the rhodopsin at equilibrium.

When this equation is substituted in equation (1), the result is

$$
\Delta D_{b}=\Delta D_{o}(I) /\left(I+I_{o}\right)
$$

because $\Delta D=\Delta D_{b}$.

Equation (v) and (vii) can be substituted directly into equation (i) to give the desired relationship

$$
D=D^{\prime}-\Delta D_{0}\left[\frac{l}{I+I_{o}}+\frac{1}{\alpha} \log \left(I+I_{0}\right)+k\right]
$$

where $k=\frac{1}{a} \log F$. This is the equation that is used to describe the smooth curves drawn through the results in Fig. 3.

Assignment of constants. In principle all of the constants in equation (2) can be derived from separate and independent experiments except $D^{\prime}$ (the pupil size in full dark adaptation) which in Fig. 3 has been given the value of $7.5 \mathrm{~mm}$. However, the precise psychophysical determination of $F, \Delta I_{o}$ and $I_{D}$ under the appropriate circumstances (ganzfeld background and test flashes) offers some technical difficulties which have been obviated by selecting $I_{D}$ and $k$ in the following way: $I_{D}$ was determined by finding in Fig. 3 the brightest background which had no obvious effect on pupil size $(-1.5 \mathrm{log}$ scotopic td) and that value of $k$ was then calculated which defined the pupil dia. of N.O. at 1 td.a was measured by RUSHTON (1961) and by ALPERN (1971) on rod monochromats and by ALPERN et al. (1970) on normals. The value of 12 obtained in the latter two studies is used for the curve in Fig. 3 though it may be somewhat low. Assuming a WeberFechner fraction of $40 \mathrm{msec}$ (AquilaR and STILES, 1954) the calculated value of the absolute threshold in full dark adaptation would then be 0.0064 scotopic td sec-a high estimate, but perhaps not unreasonably so in view of the rather large "dark" light (due, no doubt, to stray light in the room from the monitor of the pupillometer).

The value of $I_{0}=27,000 \mathrm{td}$ was measured on one of the present observers with the retinal densitometer and reported in a previous publication (ALPERN, 1971). This has since been confirmed on one of the other two subjects. $\Delta D_{0}$ is seen in Fig. 1 to be $4.5 \mathrm{~mm}$.

Acknowledgements-Assisted by a grant EY-00197-13 from the National Eye Institute. We thank Dr. F. MaAserdvaAg who helped us in many ways, and our subjects, Dr. Mark Hollins and Miss Trudy Villars. Dr. OHBA was also assisted by the Walter B. Parker fund of the University of Michigan.

\begin{abstract}
Measurements of pupil size and retinal rhodopsin in the dark after a full bleach confirm the suggestion of Alpern and Campbell that pupil dia. is linearly related to the fraction of unregenerated rhodopsin. This provides a transform [equation (1)] which can be used in conjunction with current ideas of visual adaptation to infer the pupil diameter at any luminance level $(\log I \leq 5.0$ scotopic td) in equilibrium viewing in a uniformly illuminated ganzfeld. Experimental determinations of such values on three normal subjects are in reasonable accord with expectation.
\end{abstract}

Résumé-Des mesures du diamètre pupillaire et de la rhodopsine rétinienne dans l'obscurité après décoloration totale confirment la suggestion de Alpern et Campbell, à savoir que le diamètre pupillaire est fonction linéaire de la fraction de rhodopsine non régénérée. On obtient ainsi une équation (1) qui peut être utilisée conjointement avec les idées classiques sur l'adaptation visuelle pour prédire le diamètre pupillaire à tout niveau de luminance (log I $\leq 5,0$ trolands scotopiques), dans l'équilibre devant un champ total de luminance uniforme. Les déterminations expérimentales sur trois sujets normaux sont en accord raisonnable avec cette prédiction. 
Zusammenfassung-Messungen der Pupillengröße und des retinalen Rhodopsins im Dunklen nach einer vollkommenen Ausbleichung bestätigen die Vermutung von Alpern and Campbell, daß der Pupillendurchmesser linear vom Bruchteil des nicht regenerierten Rhodopsins abhängt. Dies führt zu einer Beziehung [Gleichung (1)], die in Verbindung mit neueren Vorstellungen über die visuelle Adaptation, den Pupillendurchmesser mit dem Leuchtdichteniveau $(\log I \leq 5,0$ scotopic td) in einem gleichmäßig beleuchteten Ganzfeld in Beziehung setzt. Die experimentellen Werte dreier normaler Testpersonen stimmen gut mit den erwarteten überein.

Резюме-Измерения величины зрачка и родопсина сетчатой оболочки, после полного его обесцвечивания, подтверждает предположение Альперна и Кемпбела, что диаметр зрачка линейно связан с фракцией нерегенерированного родопсина.Это предусматрнвает преобразование [уравнение (1)], которое может быть использовано в связи с электрической гипотезой зрительной адаптации, для того чтобы сделать заключение о диаметре зрачка при любом уровне яркости ( $\log 1<5,0$ скотоп. трол.) при равновесии, наблюдаемом в однородно освещаемом поле (ganzfeld). Экспериментальные измерения этих величин у трех нормалыных лиц находились в удовлетворителном согласии с ожидаемыми результатамн. 